\title{
Erratum to: Behavioral Inhibition and Anxiety: The Moderating Roles of Inhibitory Control and Attention Shifting
}

\author{
Lauren K. White • Jennifer Martin McDermott • \\ Kathryn A. Degnan • Heather A. Henderson • \\ Nathan A. Fox
}

Published online: 21 October 2012

(C) Springer Science+Business Media New York 2012

Erratum to: J Abnorm Child Psychol 2011; 39, 735-747

DOI 10.1007/s10802-011-9490-x

The authors would like to note an error in the method section of this paper. The error is on page 739 in the description of the number of trials in the dimensional change card sort (DCCS) task. The task included 6 preswitch cards (three blue trucks and three red stars) and 6 post-switch cards (three blue trucks and three red stars), and not 8 cards per switch phase as originally described in the paper. This error has no implications for the analysis or the reported results, as data were analyzed as percent of correct trials passed by each subject. This percent variable was calculated on the 6 trials.

The online version of the original article can be found at http://dx.doi.org/ 10.1007/s10802-011-9490-x.

L. K. White $(\bowtie) \cdot$ K. A. Degnan $\cdot$ N. A. Fox

Department of Human Development, University of Maryland,

3304 Benjamin Building,

College Park, MD 20742, USA

e-mail: 1white5@umd.edu

J. M. McDermott

Department of Psychology, University of Massachusetts,

Amherst, MA, USA

H. A. Henderson

Department of Psychology, University of Miami,

Miami, FL, USA 